\title{
Infancia y pandemia: Crónica de una ausencia anunciada
}

\section{Childhood and the pandemic: Chronicle of an absence foretold}

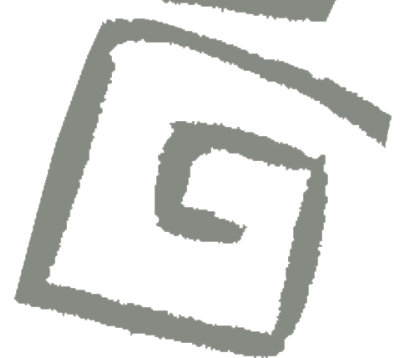

Ester Massó Guijarro ${ }^{1}$

${ }^{1}$ Doctora en Filosofía y Antropología. Profesora Titular, Departamento de Filosofía I, red Ética salubrista para el Activismo el Cuidado y la Observación Social (ESPACYOS); FiloLab; Universidad de Granada Granada, España. $\bowtie$ (iD)
RESUMEN La infancia es el sur del virus, como ha visibilizado la pandemia de COVID-19: un mundo donde el cuidado no es un valor escogido desde el deseo, y donde la voz infantil es silenciada en virtud de una injusticia epistémica ancestral. Así, la transformación que las sociedades humanas están experimentando debido a la COVID-19 ha impactado significativamente en los derechos de la infancia, a niveles micro y macro. En España, como país especialmente golpeado por la pandemia, encontramos que tanto la primera infancia (a través especialmente de la violencia obstétrica) como ella misma en todas sus fases, están siendo víctimas de un paradigma adultocéntrico de control e injusticia epistémica basales. En este ensayo se analiza y discute algunas de las consecuencias negativas observadas en este país con relación al cuidado y el confinamiento de menores y sus familias, acaecidas a raíz de la pandemia, considerando que la crisis desencadenada por la COVID-19 puede ser una oportunidad para visibilizar situaciones de injusticia ancestral para con la niñez.

PALABRAS ClAVES Cuidado del Niño; Crianza del Niño; Pandemia por el Nuevo Coronavirus 2019; Maternidades; España.

ABSTRACT As the COVID-19 pandemic has made visible, childhood is the virus's proverbial south: a world where care is not a value chosen from a place of desire, and where children's voices are silenced at the hands of an ancestral epistemic injustice. Thus, the transformation that human societies are undergoing due to COVID-19 has significantly impacted the rights of children, both at the micro and the macro levels. In Spain - a country that has been particularly hard-hit by the pandemic - we find that both infancy (especially through obstetric violence) and childhood at all its stages fall victim to an adultcentric paradigm based on control and epistemic injustice. This essay analyzes and discusses some of the negative consequences observed in this country related to the care for and the confinement of minors and their families - which has occurred as a result of the pandemic - and considers that the crisis triggered by COVID-19 may be an opportunity to shed light on situations of ancestral injustice towards children.

KEY WORDS Child Care; Child Rearing; 2019 New Coronavirus Pandemic; Maternity; Spain. 


\section{INTRODUCCIÓN}

Antes de comenzar, deseo incluir una nota metodológico-hermenéutica, como justificación antropológico-filosófica de mi ensayo: estas reflexiones han nacido y se han desarrollado al calor de la pandemia, en gran medida en confinamiento, sobre la base de versiones preliminares ${ }^{(1,2)}$, y en el marco -entre otrosdel grupo ESPACyOS ("Ética Salubrista para la Acción, el Cuidado y la Observación Social"), igualmente alumbrado durante el primer confinamiento en la pasada primavera española. Así, en sustitución de una etnografía, este texto se ha desarrollado a partir de un trabajo de campo novedoso, aunque no por ello menos auténtico y genuinamente antropológico: a través del diálogo social que supone la interlocución tanto a través de la citada red, entre otras, como, sobre todo, a través de los intensos contactos virtuales al respecto de los temas que nos ocupan, e igualmente bebiendo de forma crucial de la bibliografía gris (noticias de prensa, blogs, etc., de candente actualidad), dado que la velocidad con la que se transmiten y varían las diversas noticias, resoluciones, políticas y evidencias sobre el virus, desde la declaración pandémica, solo ha sido comparable a la viralidad de propio SARS-CoV. Tiempos nuevos (antropocénicos) requieren de miradas y escoplos, también, pioneros.

En cuanto a ESPACyOS, se trata de una red de trabajo multidisciplinar conformada por profesionales de bioética clínica, medicina, antropología, salud pública, sociología y filosofía, que trabajamos en diferentes ámbitos asistenciales y académicos. A raíz del inicio de la pandemia de COVID-19, decidimos unir esfuerzos para explorar líneas de trabajo conjuntas relacionadas con la ética salubrista y social. Uno de los diversos resultados logrados hasta la fecha es el número titulado "Ėtica i salut en temps de pandèmia. Reflexions sobre cures i justícia social" publicado en 2020 por la revista Enrahona: An International Journal of Theoretical and Practical Reason.

\section{Malos tiempos para la infancia: ¿artículos o macarrones de colores en la pandemia?}

\begin{abstract}
En su casa, las piedras de las paredes imponían una ley ancestral que dictaba que los niños debían mirar al suelo cuando eran sorprendidos haciendo algo inconveniente. Debían mostrar la nuca, dóciles como ofrendas o víctimas propiciatorias. Dependiendo de la gravedad del delito, los pescozones serían todo el castigo o sólo el preámbulo de una paliza mayor [...] Flameaban líneas rojas en sus costados como recuerdos de las fustas de los amos. Las mismas que en el secarral sometían a niños, mujeres y perros. ${ }^{(3)}$
\end{abstract}

Hace poco tiempo, leí en un artículo divulgativo cómo, para criticar la ampliación de la "brecha de género" en ciencia a raíz de la pandemia de COVID-19 en España, un profesor universitario se lamentaba de esta guisa sobre los efectos del confinamiento en los currículos académicos de los progenitores: "Cuando acabe esto los investigadores sin hijos tendrán escritos dos artículos o un capítulo de libro. Los padres, nuestro nombre con macarrones de colores"(4).

Hace mucho tiempo que no leía, como madre y como académica española, una frase $\tan$ fea. Triste y ofensiva, pese a (seguro) las mejores intenciones de su autor. En concreto, la parte fea del mensaje es que ese profesor (padre a la sazón, hemos de entender) se "lamente" de eso justamente. Que los términos de la vindicación no aparezcan invertidos: las personas que viven el privilegio del cuidado libremente escogido de sus criaturas (durante el confinamiento, de manera "exacerbada"), disfrutarán de tamaño regalo en forma de arte doméstico (en lugar de, tal vez, uno o dos artículos más en su currículo académico que, no nos engañemos, en la mayoría de los casos, tampoco van a cambiar el mundo). Pero no: el mundo no parece un lugar donde las cosas sean así, ¿verdad?

Sobre la base de un mundo como el que tenemos (de manera particular en España), 
y de su imposibilidad para contemplar el cuidado (escogido, nadie nos obliga ya a procrear) como un delicado, complejo y precioso privilegio, debe prevalecer, rugir como un seísmo remoto pero cada vez más cercano, la crítica a este sistema-mundo patriarcal-capitalista como el que habitamos.

Si la niñez pudiera ser abolida, el capitalismo la aboliría. Sin temblarle el pulso. Naceríamos ya (personas) adultas, con la oportuna edad, listas para producir. $\mathrm{O}$, como ahora, mientras eso no sea viable, que se note lo menos posible que hay infancia a nuestro alrededor. Si una mujer pare (o, mejor, si no pare, si puede evitarlo, si puede subrogarlo en mujeres menos favorecidas... vientres de alquiler, idealmente fábricas para infantes si recordamos tantas clásicas distopías), que se note lo menos posible... en su cuerpo, a su alrededor, en su familia, en su trabajo. Guardería a las escasas (insultantemente pocas) semanas de la criatura y la mujer "como nueva" -recién parida, glamurosa y atendiendo a las visitas ${ }^{(5)}$-, estupenda en su línea recuperada como si nada hubiera pasado. Que no haya leche, que no se note en la carne, en el fluido, que ha habido embarazo y parto y (acaso) lactancia.

En cuanto a la referencia a la maternidad subrogada, no deseo aquí entrar en su compleja polémica; me refiero aquí para esta crítica exclusivamente a las formas de subrogación de embarazo que suponen menoscabo patente e incluso ilegal de derechos para madres y criaturas, como es tan habitual. La persona lectora interesada en un abordaje crítico, puede consultar el número titulado "Cuestiones abiertas sobre la gestación subrogada"(6), con distintas perspectivas y enfoques al respecto.

Sobre las distopías citadas, pensemos por ejemplo en Un mundo feliz (1932), donde Aldous Huxley describía una Humanidad que se había "librado" de la supuesta condena sacrificial de tener que gestar su descendencia en el propio vientre. Unas décadas más tarde, la feminista Sulamith Firestone Ilegó a considerar el embarazo como una deformación del cuerpo, un sacrificio individual (personal) en favor de la especie (global). Estas visiones de la maternidad han sido ampliamente revisadas y ferozmente contestadas por diversos feminismos contemporáneos, aunque ello escapa de los objetivos de este ensayo ${ }^{(7)}$.

Regresando a nuestra cita original de los macarrones y los artículos, lo que más me duele de aquella frase, tan lesiva universalmente para la infancia y su cuidado, entre otras fealdades, es que sigue transmitiendo, de forma acrítica, el mensaje de que criar es una carga y lo bueno es investigar y publicar; que nosotras las mujeres (y los hombres que participan de ello) perdemos por estar criando más y publicando menos. $Y$, por desgracia, eso en sí en un hecho en lo financiero: vivimos en un mundo donde, por lo general, la maternidad nos empobrece en términos económicos y de prestigio social. De ello nos estamos ocupando en movimientos feministas sobre la maternidad en España como el que aúna la Asociación Petra Maternidades Feministas, aunque las reclamaciones al respecto desde la economía feminista sean ya antiguas ${ }^{(8,9)}$. Y la culpa no es de la maternidad, sino del mundo (de la estructura social, entiéndase). Es como si, cuando la sexualidad oprimía sistemáticamente a las mujeres (y aún lo hace, a menudo), hubiéramos resuelto que el problema era de la sexualidad misma (y no del patriarcado, entre otros) y que la solución era no practicarla, erradicarla para las mujeres.

Pero ello es otra cuestión, y lo que aquí deseamos vindicar es algo de fondo, de estructura: lo que aquí señalamos, denunciamos, desde la antropología y la filosofía de la crianza, es que nunca siquiera se insinúa que esos hombres-padres que no crían -o lo hacen menos- se están perdiendo también algo grande (dejando a un lado que están además haciendo dejación de una responsabilidad crucial), algo mucho más grande en realidad; que, por esas jornadas enteras dedicadas al trabajo, se están perdiendo algo inmenso. Algo, además, que ya es (o debería ser) elegido en nuestra sociedad, como es generar una criatura humana. No desde el mandato, sino desde el deseo ${ }^{(10)}$.

No: eso ni se insinúa, ni se atisba. El mundo aún no es un lugar preparado para 
ello. Ni siquiera (o menos que nunca) en tiempos de pandemia.

Claro que hay que reclamar, de una vez por todas, que se financie el cuidado, porque es algo grande, algo insustituible (no, la institucionalización y la externalización del cuidado no son lo mismo), algo radical para el ser humano y su devenir. Si se financia públicamente la ciencia, si se financia escribir un artículo, ¿por qué no el cuidado, en su puridad?

¿Por qué el cuidado no vende, está devaluado, desprestigiado? Más concretamente, aquí, el cuidado de niñes, de la infancia. Y la casa se quedó sola ${ }^{(11)}$ o ahora, lo que es peor (o, como mucho, no mejor), con progenitores teniendo que teletrabajar a la vez que coordinan el telecole de sus criaturas, mientras el día sigue teniendo sus habituales 24 horas, hasta nueva orden.

Como recuerda el filósofo Jordi Carmona ${ }^{(12):}$ "Los derechos son propiedad de un sujeto, de un sujeto propietario, entre otras cosas, de derechos. En cambio, la obligación se tiene con respecto a alguien o algo que no es el yo, alguien o algo que no poseo, sino que es libre y común". Así, hemos de reclamar la condición ética en esa forma de "obligación" en el cuidado que, insisto, no es en realidad tal o no debiera ser, ya que el mandato social de la progenitura se ha disuelto $y$, por tanto, elegir la crianza es un camino de libertad (comprometida, como todas las libertades reales).

El problema es que, si no subvertimos escalas de valores, estamos siempre en lo mismo. Las mujeres, para demostrar que valemos (tanto como un hombre), tenemos que hacer-participar de todos esos mandatos/placeres y eso, hasta cierto punto y si lo queremos, es bueno... pero nunca llega que los hombres, para demostrar que valen (tanto como una mujer), quieran participar de ciertas tareas... insisto, no como una condena sacrificial que hay que compartir, sino como un valor no menos fundamental (para mí, para tantas personas, mucho más fundamental) que escribir dos artículos más o menos cuando acaece una pandemia desconocida.

Para no dar una sensación de enfrentamiento diádico (mujeres versus hombres) que estoy muy lejos de pretender, matizaré todavía más: nunca llega un mundo que haga hospitalario el hecho de que los hombres reclamen -activa y formalmente- participar de ciertas tareas (no me estoy refiriendo a la cuestión de los permisos intransferibles en España, que es notablemente diferente y que ha constituido mucho más una forma de nueva discriminación a las mujeres-madres que una atribución de derechos a los hombres o a las criaturas; pero ello, de nuevo, es otro tema inabordable aquí).

A menudo insto a mi alumnado a que piense por qué hubo un movimiento sociopolítico de mujeres reclamando poder "trabajar" (desempeñar empleos remunerados en espacios públicos, reconocidos como tales, etc.) o, incluso, poder usar pantalones, y nunca hubo un movimiento sociopolítico de hombres reclamando formal y activamente cambiar pañales, acunar bebés o usar faldas. Lo más parecido, y ni se acerca, son los actuales movimientos de nuevas masculinidades, que bienvenidos sean y que proliferen. Pero nada que ver con eso que llamamos "feminismos". La obra ya antigua (1977) de la feminista noruega Gerd Brantenberg, Las hijas de Egalia ${ }^{(13)}$, de tremendísima vigencia y que también recomiendo mucho a mi (bendito) alumnado, trata precisamente de ello e ilustra la desigualdad radical a través de una metáfora atroz y poderosa, que muestra con nítida intuición lo que explican las grandes teorías feministas.

Defendemos aquí una visión ampliada del feminismo que comprenda, con Casilda Rodrigáñez ${ }^{(14)}$, el androcentrismo como un ejercicio de supremacía simbólico-práctica no solo sobre mujeres sino, también, sobre la infancia (reino infantil) y sobre lo no-humano (reinos animales y vegetales, ecosistémicos); esas fustas de los amos que someten en el secarral de Carrasco -en la cita inicial- a niños, mujeres y perros.

Los factores de corrección que tengan en cuenta labores de cuidado (crianza entre ellas, aunque se trate de un cuidado singularmente distinto a otros) son sin duda irrenunciables e inaplazables. El cuidado, sin Ilevar aparejado un correlato de apoyo económico, 
de política pública constituida como tal, conllevará siempre discriminación y exclusión. Será una burla, un trampantojo de derechos. Como tantos otros.

\section{Datos para roer, palabras para pensar: la infancia en disputa}

Los niños deben ser muy indulgentes con las personas mayores [...] nunca pueden comprender algo por sí solas y es muy aburrido para los niños tener que darles una y otra vez explicaciones. ${ }^{(15)}$

En un comentario publicado en la revista Pediatric, respecto de la transmisión de la COVID-19 en la infancia, los autores afirman que la niñez no tiene la culpa ${ }^{(16)}$, frente a aquellas reacciones iniciales que todavía prevalecen en gran medida en la praxis colectiva, sobre la supuesta condición "supercontagiosa" de un ejército de criaturas asintomáticas que obraba de transmisor silencioso. La infancia no es transmisora significativa de la pandemia de COVID-19, concluyen los autores sin ambages. A mayor abundamiento:

A casi seis meses de la pandemia, las pruebas acumuladas y la experiencia colectiva sostienen que los niños, en particular los niños en edad escolar, son impulsores mucho menos importantes de la transmisión del SARS-CoV-2 que los adultos. Por lo tanto, se deben considerar seriamente las estrategias que permitan que las escuelas permanezcan abiertas, incluso durante los períodos de propagación del COVID-19. Al hacerlo, podríamos minimizar los costos sociales, de desarrollo y de salud potencialmente adversos y profundos que nuestros niños continuarán sufriendo hasta que se pueda desarrollar y distribuir un tratamiento o una vacuna eficaz o, en su defecto, hasta que alcancemos la inmunidad colectiva ${ }^{(16)}$ (Traducción propia del inglés)
Ya en mayo de 2020, en realidad, otra renombrada revista científica publicó que les niñes no eran "supercontagiadores" y que era hora de volver a la escuela, y desde muy pronto se instó a priorizar los derechos infantiles en la respuesta a la pandemia ${ }^{(17)}$. Como precisan Rosenthal et al. ${ }^{(18)}$ :

\begin{abstract}
Muchos niños ya desde antes no alcanzaban su potencial de desarrollo o afrontaban dificultades para crecer $y$ desarrollarse debido a barreras de múltiples niveles, incluyendo las que resultaban de la pobreza o la falta de hogar. Sin embargo, el COVID-19 ha agregado otra capa de riesgo totalmente nueva. ${ }^{(18)}$ (Traducción propia del inglés)
\end{abstract}

Destaca también este impacto diferencial en función del género ${ }^{(19)}$ y se reconoce como una cuestión crucial el impacto psicológico, entre otros, del cierre de escuelas para con la salud de infancia y adolescencia ${ }^{(20)}$.

Las consecuencias de las medidas de contención pandémica para con los derechos de bebés y neonatos, en relación con los derechos reproductivos de sus propias madres $^{(21)}$, entrañan su propia y autónoma gravedad ( $y$ en la que no entramos a fondo en esta reflexión): la COVID-19 ya ha sido catalogada como factor de riesgo de violencia obstétrica ${ }^{(22)} y$, como sabemos, esta no se ejerce solo sobre la parturienta sino también sobre el bebé; es una violencia intrínsecamente bidireccional, por así decir.

Todos los estudios ${ }^{(23)}$ hasta la fecha coinciden, en definitiva, en señalar las severas implicaciones del confinamiento para con la infancia ${ }^{(24)}$, comparativamente con otros grupos sociales, y de las medidas de contención pandémica en general, que conllevan un aumento notable de la vulnerabilidad infantil(25), revelada incluso en el aumento de tasas de maltrato, abuso y violencia contra les niñes, más destacable aún en infancia institucionalizada $^{(18)}$. La infancia así ha de ocupar un lugar central en la recuperación y la planificación, durante y tras la pandemia. Sin embargo, como denuncia la socióloga Jimena Manti$1 \mathrm{a}^{(26)}$, ¿qué pasó con el confinamiento infantil 
que no entró de lleno en la agenda pública? ¿Qué pasó que en España llegamos a permitir, durante el primer confinamiento, que pasearan las mascotas y no las criaturas? ¿Qué pasó que todavía en diciembre de 2020 e incluso a inicios de 2021, los parques siguen cerrados y los bares abiertos? (retomaremos la cuestión de los parques, dada su tremenda relevancia de varios tipos, más adelante).

Contra tanta arbitrariedad, y como señalan Viner et al.(23), las medidas de mitigación de la pandemia que afecten al bienestar de la infancia solo se han de tomar si existe evidencia contrastada de que ayudan, porque de lo que sí hay muchas pruebas es de que son dañinas.

Lo que Ilama Boaventura de Sousa San$\operatorname{tos}^{(27)}$ la "trágica transparencia del virus", nos permite ver con más lucidez o, al menos, más luz, algo que siempre ha estado ahí, que lleva mucho tiempo ahí: la infancia ha sido y es una de las grandes maltratadas, simbólica y prácticamente, desde los orígenes de esta pandemia, a causa de su discriminación esencial. Como afirmó Carolina del Olmo(28) sobre los "pequeños sujetos de segunda": "La crisis del coronavirus y el confinamiento estricto de la infancia evidencian el negacionismo de los niños y niñas en la sociedad española".

$Y$ es que les niñes, a pesar de su reconocida (y tan cacareada) resiliencia, en muchos aspectos carecen de recursos de madurez cognitiva que sí disponen las personas adultas. Así, también la salud psicológica ha de ser especialmente protegida en relación con la intensa modificación de las rutinas vitales cotidianas que están teniendo que asumir; hasta la forma de comunicarse con la infancia y narrar lo que está sucediendo son cuestiones que están ameritando discusiones fundamentales. En términos de Freire ${ }^{(29,30)}$ :

No solo deberíamos haberles tenido en cuenta [a les niñes] al diseñar la estrategia para superar la pandemia. También es urgente que les consideremos, que legislemos con sensibilidad e inteligencia sobre su caso, si no queremos incurrir, como sociedad, en un delito de negligencia y abuso.

Se sabe que "in-fancia' significa, literalmente, ausencia de habla", como recuerda Jorge Larrosa $^{(31)}$ en su magnífico ensayo $P$ de profesor. $\mathrm{Y}$, como precisa Pedro Yagüe $^{(32)}$ en su perspicaz reflexión sobre infancia y política en Agamben y Rozitchner, desde los albores de la filosofía política la infancia es abordada como ámbito reflexivo íntimamente ligado al problema de la vida humana en común; todo ello, pese a su posterior y escasa problematización en la teoría contemporánea. Así, sin duda, complejizar, pluralizar la infancia -las infancias ${ }^{(33)}-$, como concepto en disputa, es hoy importante; pero, sobre todo y en primera instancia, considerarla.

Todo esto nos ha permitido pensar, una vez más, en la infancia como valor y como política (no esa infancia despolitizada, comercializada, institucionalizada) y en el confinamiento como desafío político. Igual que se habla del "sur geográfico" (metafórico de tantas cosas) del virus ${ }^{(27,34)}$, podemos hablar de ello con la infancia. La infancia es el sur del virus. Como siempre, ellas, las criaturas, no pueden pronunciarse. Tampoco en esto. No tienen voz pública política reconocida, no votan, no ganan dinero, no se sindican, no trabajan. Se habla por ellos, cada cual como mejor considera o juzga. Como precisa Freire $^{(30)}$.

Aunque no son una población de riesgo específica, se han convertido en el grupo de edad más perjudicado por la gestión del confinamiento. Más incluso que los animales domésticos, a los que el texto en el que se decretó el estado de alarma hace referencia varias veces [...] Ilamar a la reflexión sobre la necesidad de pensar en los derechos de la infancia durante este confinamiento, tal y como se ha hecho en países como Francia, Bélgica, Holanda, Alemania. 
Acciones, parques... y mucho más que parques: la injusticia epistémica sobre la infancia

\begin{abstract}
¡No corrás con los zapatos nuevos que los deshacés! ¡No saltés sobre el sofá que lo destrozás! ¡No te arrastrés por el piso que despedazás la ropa! ¡iDecime de qué te sirve ser niño, si no te dejan ejercer!! (Reclamo de Miguelito, viñeta de Mafalda, Quino).
\end{abstract}

Diversos movimientos ciudadanos, vindicaciones, peticiones de firmas destinadas a instituciones varias por parte de distintas plataformas, se vienen sucediendo sin descanso desde el inicio de los confinamientos en España, reclamando empatía y respeto ${ }^{(30)}$ a los derechos y necesidades de la infancia en la crisis pandémica. Las propuestas políticas de la Asociación Petra Maternidades Feministas, por ejemplo, tras el advenimiento de la pandemia, incluyen específicamente campañas de prestaciones regulares por infante a cargo, ahora en función del cuidado, si el principal cuidador trabaja fuera del hogar o teletrabaja.

De este movimiento contestatario, destaca en España, por diferentes motivos, la queja concreta ${ }^{(35)}$ por los cierres de parques "Reabran los parques y jardines de Granada. Las niñas y niños lo necesitan \#ParquesAbiertos". Pese a los muchos intentos de desmentir falsas creencias sobre infancia y coronavirus ${ }^{(36)}$, también con relación a los espacios al aire libre, vuelven a cerrar los parques.

A mayor abundamiento y para su más oportuna comprensión, se ofrecen algunos datos detallados sobre esta cuestión. Las medidas restrictivas relativas al cierre de parques, análogamente a muchas otras políticas específicas en España, poseen, en general, un carácter autonómico y delegado con respecto al gobierno central; es decir, se articulan por comunidades autónomas de manera diferenciada, si bien es cierto que, como en muchos otros países, la declaración de una emergencia nacional puede suponer alteraciones momentáneas de esta descentralización. Cabe recordar que España tiene un sistema político en forma de comunidades autónomas que poseen un altísimo grado de independencia con respecto al Estado central, asumiendo muchas competencias delegadas, algunas de las más fundamentales, como la educación, la sanidad o muchos aspectos de la fiscalidad. De facto, en un primer momento de la pandemia, cuando el gobierno español decretó, el 14 de marzo de 2020, el primer estado de alarma y se prescribió el confinamiento poblacional, por defecto quedó clausurada toda posibilidad no solo de acceso a parques públicos (esto, como resulta evidente, fue solo un corolario de toda la situación, entonces y después), sino incluso de poder dar un paseo con menores por la calle. Sí se permitió, en cambio, pasear a las mascotas (perros, principalmente) para que hicieran sus necesidades.

Francia, Alemania, Reino Unido, Portugal, Italia, Suiza o Bélgica permitieron, desde el inicio, que sus menores acompañados de cuidadores salgan a la vía pública, cada cual con distintos matices o restricciones. Frente a estos ejemplos, España era el único país cuyos menores no pudieron salir de su hogar, en absoluto y bajo ninguna circunstancia, desde el 15 de marzo hasta el 26 de abril de 2020, cuando se consintió que personas de 13 años o menos pudieran salir una hora al día para pasear, jugar y hacer ejercicio, aunque siguió estando prohibida la utilización de parques infantiles, y las salidas se limitaron a la franja horaria de las 9:00 a las 21:00. Ello supuso, así, más de seis semanas, casi cincuenta días completos, en que los perros tuvieron más derechos que les niñes (y ello, asumiendo la conveniencia de que los derechos de los animales no se vean limitados en ningún caso; no queremos igualar por abajo, sino por arriba, contra el especismo... pero también contra el adultocentrismo).

Con respecto a los parques, destaco a modo de ejemplo significativo la movilización sucedida tras su cierre en la Comunidad de Madrid al inicio de la segunda ola: esta medida supuso la creación de una petición con recogida de firmas en la plataforma Change.org, denominada ¡NO CERRÉIS LOS PARQUES a los niños de Madrid! Queremos saber la explicación CIENTÍFICA ${ }^{(37)}$, en 
septiembre de 2020, dirigida a la Comunidad y al Ayuntamiento de Madrid. Con 13.550 firmas, logró su objetivo apenas un mes después, y el Ministerio de Sanidad revocó la prohibición del uso de parques infantiles en la orden ministerial, que había recogido entonces las nuevas medidas de restricción para la contención de la pandemia, en su repunte tras el verano. Esta rescisión implicó que ningún ayuntamiento quedaba obligado a cerrar sus parques infantiles (si bien la medida devenía elegible, es decir, sí podían hacerlo de forma discrecional, como sucedió en muchos casos).

Numerosos medios de comunicación, como televisiones autónomas y nacionales públicas y privadas (por ejemplo, Telemadrid y Antena3), aparte de los medios virtuales, se hicieron eco de esta petición y contribuyeron sin duda a su éxito, como reconoce su impulsora original Nuria del Olmo ${ }^{(38)}$. Igualmente, uno de sus elementos cruciales, de interés general y que motivó probablemente su incontestabilidad, fue su apelación sin ambages a lo que llamó "la explicación científica" ("queremos saber la explicación científica"). Así, la propia petición solicitaba, muy oportunamente, una "EXPLICACIÓN BASADA EN LA EVIDENCIA CIENTÍFICA y que justifique CON DATOS esta restricción" (las mayúsculas son originales del texto peticionario. Así, sus impulsores no querían ceder al miedo indiscriminado o al bulo (tan poderosos en esta pandemia que ya están suponiendo campos de especialización explícitamente sindémicos), sino que apelaba a la fundamentación científica, a los datos, la razón, la evidencia, la luz ilustrada, para una medida que desde luego perjudicaba grandemente a un sector, ya por sí, especialmente golpeado por la pandemia y silenciado en sus bambalinas.

Destaca otra petición análoga en Change. org, de noviembre de 2020, en una ciudad capital de provincia al sur de España, denominada "Reabran los parques y jardines de Granada. Las niñas y niños lo necesitan \#ParquesAbiertos"(39), y dirigida a la Consejería de Salud y Familias, el Ayuntamiento de Granada y la Junta de Andalucía (órganos autonómicos de delegación gubernamental). Redactada en términos similares y con idéntico reclamo, ameritó sin embargo desigual éxito ya que, con 4.101 firmantes, no alcanzó las 5.000 necesarias para formalizarse y surtir efectos de impacto. Nótese que este cierre de parques (que continúa hoy en esta ciudad, como en tantas otras) es coetáneo, entre otras medidas $y$, a modo de ejemplo significativo, con la permisión de que los bares continúen abiertos, con personas comiendo y bebiendo en su interior, sin mascarilla, aunque existan datos contrastados sobre los riegos de contagio en interiores por aerosoles sin la protección constante del barbijo. Igualmente, eses niñes que no pueden jugar en parques públicos, sí acuden a la escuela cada día, sin haberse bajado la ratio de alumnado en la inmensa mayoría de los casos o haberse optimizado (ampliado) el espacio de aula, aumentado el tiempo de recreo, etc. No pretendo criticar con esto que sigan abiertas las escuelas; antes bien, creo que es fundamental que lo hagan, pero sí enfatizar la inconsistencia para con la medida del cierre de parques.

En estos momentos, avanzado ya el inicio de 2021, con España en la terrible cúspide de su tercera ola, con los datos más desfavorables desde el inicio, hace ahora un año de la pandemia por coronavirus, las diversas comunidades y sus ayuntamientos cierran parques a discreción, y con discrecionalidad, sin que exista una norma unánime de constricción nacional. Todo ello, pese a que las evidencias científicas (tan justamente reclamadas por las plataformas cívicas) apuntaron desde hace meses hacia la no peligrosidad de los parques para con los contagios $y$, antes bien, su deseabilidad, al tratarse de espacios abiertos (y gratuitos), etc., frente a tantas otras incongruencias que siembran la disensión social y la falta de confiabilidad en clase política.

$\mathrm{Y}$, así, lo de los parques no tiene nombre. Bueno, sí, tiene uno: despropósito. Social, humano, universal. Ya se ha probado no solo que no suponen un riesgo, sino que habría que animar a ir a ellos, como afirma el médico Javier Padilla ${ }^{(40)}$, según toda la evidencia científica disponible hasta el momento.

Y lo de los parques no es una cuestión baladí: son de los pocos espacios municipales 
y gratuitos (no contamos parques de bolas en centros comerciales o similares, que no son municipales ni mucho menos gratuitos) destinados específicamente a la infancia, a su recreo, al aire libre, donde pueden libremente ser criaturas, jugar, gritar, patalear $y$, en definitiva, ejercer, como reclama el pobre Miguelito, el más chiquito y levantisco de les amigues de Mafalda. Así que cerrarlos, no, no es trivial: es práctica y simbólicamente importante. Es político.

Afirma con lucidez la divulgadora científica Deborah García(41), en su reflexión a favor de la apertura de parques: "Así que esto no va de política, sino de ciencia". Y tiene razón. El problema es que la política es todo, lo inunda todo, es la atmósfera hasta (o sobre todo) para la ciencia. La política entendida en su sentido fuerte, claro, como asunto de la polis, de la res publica, la cosa pública. Así que tenemos que repolitizar el asunto hasta sus confines, hasta sus últimas consecuencias.

$\mathrm{Y}$ es que esto va de parques, pero de mucho más. Mucho más que los parques (aunque también estos) es lo que hay que conquistar en esta forma de exclusión, de segregación, tan antigua como el ser humano. "La infancia será siempre el estado subversivo del hombre", escribe el grandioso Sánchez Piñol ${ }^{(42)}$. "Donde hay niños, existe la edad de oro", canta el inefable Novalis. Ambos tienen razón, una razón profana, no sagrada, una razón carnal y trascendente al tiempo. Y, sin embargo, ese estado "dorado" y "subversivo", en la práctica, resulta políticamente desposeído, sin atributos. Esa patria gozosa y originaria no se escucha. Es objeto, entre otras, de una injusticia epistémica. Este concepto, prodigiosamente acuñado en 2017 por Miranda Fricker ${ }^{(43)}$, apenas ya desde su albor ha reproducido notables vástagos hermenéuticos. Vástagos mestizos e insólitos: su alcance y su aplicación hoy han rebasado fronteras.

\section{REFLEXIÓN FINAL}

\section{Hasta que la dignidad se haga costumbre}

Todas las personas mayores fueron niños una vez, aunque pocos lo recuerdan. ${ }^{(15)}$

Una injusticia epistémica ${ }^{(43)}$ se produce cuando se anula la capacidad de un sujeto para transmitir conocimiento y dar sentido a sus experiencias sociales. Si esto sucede en algún grupo social de forma paradigmática (del todo acrítica y normalizada dicha anulación), es proverbialmente la infancia. De hecho, resulta notoria la ausencia que aún hallamos (una especie de metainjusticia epistémica) en los estudios con este enfoque sobre su aplicación precisamente a la infancia, a las voces infantiles. Se ha de ser justa en reconocer que la ausencia no es total: se ha usado ya este escoplo cognitivo en interesantes estudios sobre la infancia trans ${ }^{(44)}$, por ejemplo, pero sigue siendo marginal y todavía tentativo, iniciático. No se trata en absoluto de un campo de estudios críticos constituidos como tantos otros de reclamación de voces y epistemologías silenciadas ${ }^{(34)}$.

Esta suerte de injusticia se está visibilizando de una forma deslumbrante con la crisis generalizada por la pandemia de COVID-19. Marta Plaza ${ }^{(45)}$ lo afirma con dura nitidez: "El trato habitual que se da a la infancia supone quitarle voz, usurpar su discurso en aras de una supuesta mayor protección, condenar a la invisibilización social y la falta de credibilidad, y asumir sin siquiera denuncia social la vulneración cotidiana de sus derechos individuales y colectivos". Todo para el pueblo pero sin el pueblo. Adultocracia, adultocentrismo y, entre otras etiquetas posibles para abastecer de comprensión esta cuestión, injusticia epistémica, sí, también.

Porque hay que darle nombres, conferirle rostros, ponerle playas, como decía el poeta. Me refiero al vate granadino Rafael Guillén y a su poema "Un gesto para el quinto aniversario de tu muerte", dedicado a su madre, y que puede escucharse aquí recitado por su autor ${ }^{(46)}$. "A veces basta cambiar las palabras 
para comprender mejor las cosas, para que el mundo aparezca de otra manera", cavila el gran Larrosa ${ }^{(31)}$. Hay un gran poder en la enunciación, en la narración, en cómo contamos los cuentos, que son siempre la poesía de la memoria.

El término "neurotípico" o "neurotipia", cada vez de mayor predicamento, puede también aplicarse, en la discriminación que suponía su ausencia o el darlo por hecho, a la infancia: la neurotipia de una persona adulta no es la misma que la de una persona niña, que tiene que moverse más, hablar más, gritar más, igual que se ríe y sonríe muchísimo más, por fortuna, y alabadas sean las diosas.

"Esos ciudadanos pequeños, pero ciudadanos", que dice Tonucci, a quienes habría que escuchar porque "escuchar significa tener necesidad de la contribución del otro" $y$, como bien enuncia Marta Plaza ${ }^{(45)}$, "No se pueden construir sociedades, espacios, políticas... preguntando y aprendiendo solo del mundo adulto". El pedagogo italiano, Tonucci, es el autor de la propuesta, tan revolucionaria como imperiosa, sobre los consejos de infancia ${ }^{(47)}$, de la que por cierto se hizo eco el Parque de las Ciencias de Granada ${ }^{(48)}$, siempre pionero en su espíritu científico, ya desde 2004. También durante el confinamiento Tonucci ${ }^{(49)}$ contribuyó a la reflexión acerca de lo que podía y debía suponer compartir ese tiempo precioso con nuestros hijos e hijas, mucho más allá del telecole.

¿Qué queremos decir cuando denunciamos que algo nos "infantiliza", y no debiera? La voz popular lo usa pretendiendo significar un trato ilegítimo, despectivo, dispar del correspondiente a un adulto. Hasta Nelson Mandela habla en sus tremendas memorias de cómo se rebelaron en Robben Island frente a la "infantilización" que suponía verse obligados a usar pantalones cortos en la cárcel, "como los niños", dejando aparte que merecieran todos llevarlos largos, por otros motivos ajenos a una comparación etaria, y recordando sobre todo que debiera ser lectura obligada el Largo camino a la libertad ${ }^{(50)}$ del revoltoso Madiba, como manual de buenas costumbres.

Mientras el término "infantilizar" siga teniendo las connotaciones negativas que posee hoy en el imaginario popular (no necesariamente correspondiente con su definición "objetiva" en el Diccionario de la Real Academia Española), la infancia seguirá siendo ese estado subversivo y romantizado que, sin embargo, y como tantas otras subversiones, deviene en verdad subalterno y domesticado por la supremacía etaria de la adultez.

Así, frente a las lógicas edadistas, frente a la adultocracia y el adultocentrismo, descolonizar, también y, por último, la infancia -sí, la interseccionalidad también era esto ${ }^{(51)}-$ y hasta que la dignidad se haga costumbre, como gritaron desde México al mundo las tres mujeres ñöhñö, porque una disculpa no era suficiente ${ }^{(52)}$.

Hasta que llegue el día en que no esté normalizado (pese a que fue desterrado definitivamente de la legislación española en 2007) ver a un progenitor golpear a su hijo en la vía pública, en la cola un supermercado, y que nadie haga nada, lo siguiente que se piensa es: "bueno, si le pega muy muy fuerte, igual entonces sí, claro..." iY si lo que vemos es a un hombre golpear a una mujer? ¿Esperaríamos entonces a valorar el grado y eficacia del tortazo? En cambio, la criatura golpeada no solo es menor y claramente, por tanto, más vulnerable que su golpeador, sea fuerte o flojo el "manotazo": sobre todo, está a su cuidado, lo que hace la agresión más doliente, más sangrante. Hasta entonces, la dignidad infantil no será costumbre.

Y esa dignidad, esa justicia, también debieran ser más que un sueño. 


\section{REFERENCIAS BIBLIOGRÁFICAS}

1. Massó Guijarro E. La infancia, la gran perjudicada por la pandemia. TheConversation [Internet]. 26 oct 2020 [citado 30 oct 2020]. Disponible en: https://tinyurl.com/ nn3vx488.

2. Massó Guijarro E. Infancia, crianza y pandemia: malos tiempos para ser niñx [Internet]. 21 nov 2020 [citado 28 nov 2020]. Disponible en: https://tinyurl.com/37z9cfwc.

3. Carrasco J. Intemperie. Madrid: Círculo de Lectores; 2013

4. Sáez C. "Estoy fallando como investigadora y madre": la covid-19 amplía la brecha de género en ciencia. Público [Internet] 8 jun 2020 [citado 15 oct 2020]. Disponible en: https://tinyurl.com/yu5u327r.

5. Jan C. Recién parida, glamurosa y atendiendo a las visitas. El País [Internet]. 7 oct 2011 [citado 15 oct 2020]. Disponible en: https://tinyurl.com/62yv87yt.

6. Triviño Caballero R, Ausín Díez T, edit. Cuestiones abiertas sobre la gestación subrogada. Dilemata. 2018;(18).

7. Massó Guijaro E. Lactivismo contemporáneo en España: ¿nueva marea sociopolítica? Journal of Spanish Cultural Studies. 2015;16(2):193-213. doi: 10.1080/14636204. 2015.1069074.

8. Waring M. Si las mujeres contaran: Una nueva Economía Feminista. Madrid: Vindicación Feminista; 1994.

9. Palmer G. The politics of breastfeeding: When breasts are bad for business. Londres: Pinter and Martin; 2011.

10. Gallo L. Ma(pa)ternidades: repensar la equidad de roles y funciones en cuanto a las tareas de cuidado. Escritura Feminista [Internet]. 27 mar 2018 [citado 15 oct 2020]. Disponible en: https://tinyurl.com/vwttxevz.

11. Cañero Ruiz J. La casa se quedó sola: Una reflexión feminista sobre la maternidad. Píkara Magazine [Internet]. 3 abr 2019 [citado 15 abr 2020]. Disponible en: https://tinyurl.com/337tm3s6.

12. Carmona Hurtado J. El problema del compañerismo en el cuidado de los hijos. El Salto [Internet]. 1 oct 2020 [citado 15 oct 2020]. Disponible en: https://tinyurl.com/ yh3kn28a.

13. Brantenberg G. Las hijas de Egalia. Madrid: Traficantes de Sueños; 1993.

14. Rodrigáñez Bustos C. La sexualidad y el funcionamiento de la dominación: La rebelión de Edipo II. Madrid: Casilda Rodrigáñez; 2008.

15. Saint Exúpery A. El Principito. Barcelona: Salamandra; 2003.

16. Lee B, Raszka WV. COVID-19 transmission and children: The child Is not to blame. Pediatrics. 2020;146(2) :e2020004879. doi: 10.1542/peds.2020-004879.
17. Munro APS, Fauss SN. Children are not COVID-19 super spreaders: time to go back to school. Archives of Disease in Childhood. 2020;105(7):618-619. doi: 10.1136/archdischild-2020-319474.

18. Rosenthal DM, Ucci M, Heys M, Hayward A, Lakhanpaul M. Impacts of COVID-19 on vulnerable children in temporary accommodation in the UK. The Lancet Public Health. 2020;5(5):E241-E242. doi: 10.1016/S2468-2667(20)30080-3.

19. Burzynska K, Contreras G. Gendered effects of school closures during the COVID-19 pandemic. The Lancet. 2020;395:1968.

20. Colao A, Piscitelli P, Pulimeno M, Colazzo S, Miani A, Giannini S.. Rethinking the role of the school after COVID-19. The Lancet. 2020;5(7):E370. doi: 10.1016/ S2468-2667(20)30124-9.

21. Massó Guijaro E, Triviño Caballero R. Parto y aborto en tiempos de coronavirus: el impacto de la pandemia en los derechos sexuales y reproductivos. Enrahonar: An International Journal of Theoretical and Practical Reason. 2020;(65):117-130.

22. Sadler M, Leiva G, Olza I. COVID-19 as a risk factor for obstetric violence. Sexual and Reproductive Health Matters. 2020;28(1):1785379. doi: 10.1080/26410397.2020.1785379.

23. Viner RM, Russell SJ, Croker $\mathrm{H}$, Packer J, Ward J, Stansfield C, et al. School closure and management practices during coronavirus outbreaks including COVID-19: a rapid systematic review. The Lancet Child \& Adolescent Health. 2020;4(5):397-404. doi: 10.1016/ S2352-4642(20)30095-X.

24. Infancia Confinada [Internet]. 2020 [citado 10 oct 2020]. Disponible en: https://infanciaconfinada.com.

25. Cluver L, Lachman JM, Sherr L, Wessels I, Krug E, Rakotomalala S, et al. Parenting in a time of COVID-19. The Lancet. 2020;395(10231):E64. doi: 10.1016/S01406736(20)30736-4.

26. Mantilla J. La invisibilidad como problema: Primeras aproximaciones a la situación de las niñas y los niños durante la política de confinamiento por la pandemia de COVID-19 en Argentina. Enrahonar: An International Journal of Theoretical and Practical Reason. 2020;65:131-139.

27. Sousa Santos B. La cruel pedagogía del virus. Buenos Aires: Clacso-Masa Crítica; 2020.

28. Del Olmo C. Pequeños sujetos de segunda. El País [Internet]. 19 abr 2020 [citado 15 oct 2020]. Disponible en: https://tinyurl.com/8wk9vvev.

29. Freire H. Coronalnfancias: Los derechos de los niños y niñas en tiempos de crisis. Heike Freire [Internet]. 16 mar 2020 [citado 15 oct 2020]. Disponible en: https:// tinyurl.com/yap89e3c.

30. Freire H. Empatía y respeto a los derechos y necesidades de la infancia en la crisis del coronavirus. Change. 
org [Internet]. 2020 [citado 15 oct 2020]. Disponible en: https://tinyurl.com/97f8c8zy.

31. Larrosa J, Reichia K. P de Profesor. Ciudad Autónoma de Buenos Aires: Noveduch Libros; 2019.

32. Yagüe P. Infancia y política en Giorgio Agamben y León Rozitchner. Anacronismo e Irrupción. 2020;10(18):254279.

33. Infobae. Día de las Infancias: por qué el Día del Niño cambió de nombre. Infobae [Internet]. 16 ago 2020 [citado 15 oct 2020]. Disponible en: https://tinyurl. com/4fkpewr6.

34. Sousa Santos B, Meneses MP. Epistemologías del Sur. Madrid: Akal; 2014.

35. \#parquesabiertos. Reabran los parques y jardines de Granada. Las niñas y niños lo necesitan \#ParquesAbiertos. Change.org [Internet]. 2020 [citado 15 oct 2020]. Disponible en: https://tinyurl.com/3pn9h7ef.

36. Paricio Talayero JM, Freire $\mathrm{H}$. Falsas creencias sobre infancia, coronavirus y confinamiento: Los niños son los principales vectores del contagio. Heike Freire [Internet]. 20 abr 2020 [citado 15 oct 2020]. Disponible en: https:// tinyurl.com/uhx3akbx.

37. Del Olmo N. ¡NO CERRÉIS LOS PARQUES a los niños de Madrid! Queremos saber la explicación CIENTíFICA. Chance.org [Internet]. 2020 [citado 10 nov 2020]. Disponible en: https://tinyurl.com/3j3d97h2.

38. Del Olmo N. ¡Victoria! Chance.org [Internet]. 2 oct 2020 [citado 10 nov 2020]. Disponible en: https:// tinyurl.com/2hwhctj5.

39. Reabran los parques y jardines de Granada: Las niñas y niños lo necesitan \#ParquesAbiertos. Chance. org [Internet]. 2020 [citado 10 nov 2020]. Disponible en: https://tinyurl.com/ydwvjwdh.

40. Oliver D, Cordellat A. ¿Tiene justificación científica la fijación con los parques infantiles en las medidas para frenar la covid? El País [Internet]. 12 oct 2020 [citado 15 oct 2020]. Disponible en: https://tinyurl.com/t6best.

41. García D. Abran los parques. El Muro, Ciencia Aparte [Internet]. 23 sep 2020 [citado 15 oct 2020]. Disponible en: https://tinyurl.com/3rv4hxm8.
42. Sánchez Piñol A. Victus. Madrid: La Campana; 2012.

43. Fricker M. Injusticia epistémica. Barcelona: Herder; 2017.

44. Guerrero Mc M, Siobhan F, Muñoz Contreras LD. Epistemologías transfeministas e identidad de género en la infancia: del esencialismo al sujeto del saber. Revista Interdisciplinaria de Estudios de Género de El Colegio de México. 2018,4:e168. doi: 10.24201/eg.v4i0.168.

45. Plaza M. Infancia Confinada: "No se pueden construir sociedades, espacios, políticas... preguntando y aprendiendo solo del mundo adulto". Píkara Magazine [Internet]. 17 jun 2020 [citado 15 oct 2020]. https:// tinyurl.com/3bbyysyb.

46. Guillén R. Un gesto para el quinto aniversario de tu muerte [Internet] 2019 [citado 15 oct 2020]. Disponible en: https://vimeo.com/238893443.

47. Asociación Pedagógica Francesco Tonucci. ¿Por qué un Consejo de Infancia? [Internet]. 2020 [citado 15 oct 2020]. Disponible en: https://tinyurl.com/3dd3vt3p.

48. Consorcio Parque de las Ciencias. Parque de las Ciencias [Internet]. 2020 [citado 15 oct 2020]. Disponible en: https://www.parqueciencias.com.

49. Pantaleoni A, Battista G. Francesco Tonucci: "No perdamos este tiempo precioso dando deberes". El País [Internet]. 11 abr 2020 [15 oct 2020]. Disponible en: https://tinyurl.com/2677arcw.

50. Mandela N. El largo camino hacia la libertad. Madrid: Aguilar; 2000.

51. Massó Guijarro E. Tullidos, bastardos y cosas rotas": diversidad funcional e interseccionalidad en 'Juego de tronos'. Dilemata. 2020;31:27-52.

52. Martínez O. "Hasta que la dignidad se haga costumbre": El demoledor discurso de una indígena conmueve a México. RT [Internet]. 24 feb 2017 [citado 15 oct 2020]. Disponible en: https://tinyurl.com/56kjy365.

Recibido: 24 nov 2020 | Versión final: 3 feb 2021 | Aprobado: 8 mar 2021 | Publicado en línea: 16 abr 2021

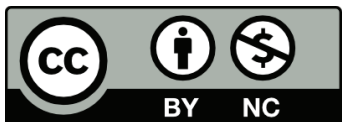

Esta obra está bajo una licencia de Creative Commons Reconocimiento-NoComercial 4.0 Internacional. Reconocimiento - Permite copiar, distribuir y comunicar públicamente la obra. A cambio, se debe reconocer y citar al autor original. No Comercial - Esta obra no puede ser utilizada con finalidades comerciales, a menos que se obtenga el permiso. 